\title{
Human Rights in a Globalized Modern World
}

\section{Golubev Stanislav Igorevich}

Kazan (Volga region) Federal University, Kremlevskaya str., 18, 420008 Kazan, Republic of Tatarstan, Russian Federation

\section{Doi:10.5901/mjss.2014.v5n24p468}

\begin{abstract}
The practice of recognition and protection of "human rights" have a long history, respectively, and from the time of arising of social rights and freedoms, passed quite a few centuries. In different parts of the world, social rights and freedoms emerged and developed ambiguous. Their recognition, consolidation, compliance, security and protection of structural represent a very significant set of principles and rules governing a wide range of social relations.
\end{abstract}

Keywords. Rights and freedoms, protection of rights and freedoms, globalization, international law, human rights.

Aiming at getting a more accomplished and a deeper insight into the problem of human rights in a globalized modern world, one may feel an irresistible desire to disclose a complex and multifaceted nature of this category as well as to show its basis and social roots.

On this account, we find it necessary to pay attention to the nature of human rights and their connection with politics and ethics in order to systematize knowledge about human rights at a time when globalization makes an integral part of the developing interstate relations [1].

At this stage of development, globalization is more than an economic process. It is characterized by some political, economic, cultural and legal aspects, which influence on the way an individual may exercise its rights in full. This is the point where, the burning necessity of exploring human rights and fundamental freedoms of an individual through globalization results from.

Owing to the fact that the modern world order has been facing several actual problems, globalization process is contrasted to these universal challenges. Nikolay Pokrovsky considers them to include the population growth processes that are uncontrollable, as well as social and economic underrun, cultural gap, problem of education (growing rate of the illiterate people), food problem, reduction of natural resources, military threat, international terrorism, and aggravation of international relations [2].

Akmal Saidov points out that "human rights determine full value of life on the planet, make an integral part of nations' culture and the highest expression of moral and legal ideals of the humankind" [3].

It is difficult to disagree with this statement, yet we should state a fact that nowadays human rights are disregarded, because modern world and society exercise some other values.

To determine the nature of human rights, it is essential we should apply a historical approach, because the very idea of human rights has a long history. Therefore, this approach to the subject under study allows us to suggest that the origin of the idea of human rights is dated back to antiquity, while modern sense of "human rights" can be traced back to the times of bourgeois revolutions.

Rapid development and emergence of the idea of human rights at the beginning of new millennium are determined both by a modern level and character of the world civilization and the previous experience of the humankind [4].

Thus, the origin of human rights is usually studied using two approaches, the first being connected with ancient times, while the second referred to the period of formation of the bourgeois class (XVII-XVIII cc.).

Today, we can single out two periods of historical development of the conception of human rights. A. Saidov, for instance, singles out three main following trends:

1) Emergence of the idea of a person, an individual, as something separate, isolated from the race, community, state; as an independent subject of law;

2) Development of legal system, codification of laws and emergence of legal institutions in the ancient times and Middle Ages;

3) Formation of the concept of universal rights and laws, their applicability to each and everyone.

With regard to this approach, we would like to suggest the idea of $V$. Nersesyants, who points of that, from the political and legal standpoint, "the theory and practice of human rights have a long and insightful history". 
With regard to all its novelty and peculiarities determined by modern level and character of the world civilization, nowadays the problem of human rights is based on a rich experience of the humankind mainly in the field of legal forms of organization of people's life on social and national levels, legal ways of governing social relations [5].

The biggest achievement of humankind in the XX c. is development and employment of the regime of the international protection of human rights and freedoms. Under international legal acts of universal character, states as subjects of the international law are obliged to enforce and protect human rights and freedoms. However, revealed in various spheres of life of the international community at different levels of intensity, globalization makes a significant influence not only on development and formation of new approaches to international regulation of interstate relations, but on the system of universal principles and norms of the international law in human rights.

Vladiimir Kartashkin writes that globalization influenced greatly on the change of such fundamental principle as international protection of human rights. It is probably connected with the fact that advantages of globalization are enjoyed by the most developed countries, while the developing states face the growth of social discontent that could probably explode all the system of the international relations. To avoid this possibility, achievements of globalization should belong to all humankind, to all national and peoples [6].

However, Academician Nikita Moiseev criticizes and raises objections to the theory of "universalization" of human rights. He explains his critical view to the theory of unversalization of human rights as appropriate for all people living in various countries in the following way - this is as much illusion as the idea of identical interpretation of the concept of "good". Any attempts to unify human rights show how imperfect this civilization or, to be more exact, some civilizations on this planet can be, mainly in the field of this general process of self-organization determining social development.

Besides, N. Moiseev excludes the possibility of global standardization of human rights because it is impossible to disregard the character of the civilization in which an individual has been raised for thousand years. With regard to this fact, rules of life were based on the principles determined by the environment [7].

On the other hand, global society develops towards realization of the value of an individual, therefore both international and national laws become more focused on an individual, and the international community gradually acquires characteristics of the global international system [8]. Igor Lukashik points out that this process is characterized by de-etatization of the international law which means that the observance of human rights in a state can be controlled externally by the international community as well as internally by its people or any individual. De-etatiation is also reflected in the fact that international law brings rights of peoples and an individual to the forefront. This is the only foundation for the international order applicable for the human civilization in the XXI c. [9].

It is under these conditions that observance of human rights and freedoms is no longer an internal matter of a state. During globalization of the international community references to a state sovereignty may afford no excuse for human rights abuse [10].

In this case balance between observance of the principle of human rights and freedoms and such fundamental principles of international law as respect for national sovereignty, non-interference in the internal affairs of the country, etc may become a point of contention [11].

In practice, the whole problem reduces itself to the question of legitimacy of the humanitarian interference, political or economic isolation of a state with massive human rights violations. It is evident that every case requires that international community should make a well-informed decision. Taking into account that all aforesaid principles possess equal legal power, it is necessary that every single decision reflecting attitude of the international community to a certain situation should be in conformity with humanitarian goals.

Such fundamental principles of international law as national sovereignty and non-interference in the internal affairs of a country are restricted to human, peoples' and individual rights. If we consider these questions in the light of attempts that are made by all international community and some particular states towards observance of the fundamental individual and civil rights and freedoms, we should not consider them as interference in the internal affairs of a country.

However, under these conditions it is essential taking assuming that peace and safety of the international community should not be exposed to unilateral military actions or to a threat of these actions from any state. Thus, any state should be deprived of an opportunity of making independent decisions about its right to a humanitarian intervention, including use of armed forces. These actions may take place only in conformity with the UN Charter and decisions of the Security Council, in cases when all other possibilities of influence on a corresponding state have been exhausted. This is the only way balanced regulation of the international relations can be made for the sake of world order.

Today, we would like to point out the assumption made by Vladimir Kartashkin, because it is nowadays that we can see social explosion on the African continent, that suffered from events that caused significant political changes and replacement of state authorities in some African countries.

To avoid getting involved into politics, we would like to discuss some other factors that influenced on such a course 
of events. Besides, it is reasonably safe to suggest that beside all other factors, this turn of events resulted from simple violation of basic human rights as well the unwillingness or even impossibility for people to live in desperate poverty.

In this respect, we would also like to add that in such complicated and controversial situations that take place in Northern African states or any other parts of the Universe we should follow human rights which should determine the limits of individual freedom and relations with the state and other individuals. Touching upon the perspectives of legal regulation, we should take into account the undeniable fact that the problem of human rights within a context of international regulation of their protection is quite well developed. It equally proves that there is a vast amount of international acts of universal character related to human rights, as well as shows deep concern of the international community to this matter [12].

However, human rights in the new millennium are characterized by the fact that their current development is in controversial conditions, which both have retained from the past times and develop now. One of such contradictions is universal globalization of social development, while on the other hand, this contradiction is represented by the willingness of certain traditional communities to emphasize their individuality by preserving their self-identity, their own special approach to human rights determined by genesis of this society and its traditions.

Processes of globalization of the modern world go in hand with ethnic and cultural self-identification of peoples that do not always accept the European values and that refer themselves to a different civilization emphasizing their individual peculiarities by insisting on their right to have their own unique culture, traditions, religion, ethic and legal norms and national identity. This may cause significant difficulties in affirming them and complicating their realization in various regions around the world.

\section{References}

Mertus, J.A. Human rights matters : local politics and nat. human rights institutions / J.A. Mertus. - Stanford : Stanford Univ. Press, 2009. $-\mathrm{XI}, 223 \mathrm{p}$.

Nikolay.E. Pokrovsky. Globlization and Regionalism: Problems of Theory and Practice // Moscow State University Bulletin. Ser. 18. Social and political sciences. 1999. № 2. - P. 24.

Akmal K. Saidov. Generally Recognized Human Rights. Edit. I. I. Lukashuk. M., 2002. - P. 3.

Convention for the Protection of Human Rights and Fundamental Freedoms, Rome, 4.XI.1950.

Vladik S. Nersesyants. Human Rights in the History of Political and Legal Though. Cited: Human Rights. Edited by E. A. Lukashev. M., 1999. - P. 35.

Vladimid A. Kartashkin. Human Rightsat the Turn of the Centuries. M., 2002. - P. 299.

Human Rights in Russia: Declarations, Norms and Life: Materials of the International Conference dedicated to the 50 years anniversary of the Universal Declaration of Human Rights // State and Law. 2000. № 3. - P. 38; Moiseev I. N. Destiny of the Civilization. Way of the Sense. M., 1998. - P. 104-109.

European Social Charter, 529 U.N.T.S. 89, entered into force Feb. 26, 1965. Part I; Part II.

Igor I. Lukashuk. Principle of Democracy in the International Law // The Moscow Journal of the International Law. Special edition, December 1998. - P. 65-66.

Protocol № 6 to the 1950 European Convention for the Protection of Human Rights and Fundamental Freedoms, E.T.S. 114, entered into force March 1, 1985.

Charter of the United Nations 26 June 1945, in San Francisco, at the conclusion of the United Nations Conference on International Organization, and came into force on 24 October 1945.

Central African Republic: UN agencies report increase in human rights violations. Date of visit 21.07 .2014 http://www.un.org/apps/news/ story.asp?NewsID=45788\#.U8zIP7GoBI0 